\title{
The effects of taxes and benefits on income inequality, 1980-2009/10
}

\author{
Authors: Grace Anyaegbu
}

Office for National Statistics 


\section{A National Statistics publication}

National Statistics are produced to high professional standards set out in the Code of Practice for Official Statistics. They are produced free from political influence.

\section{About us}

\section{The Office for National Statistics}

The Office for National Statistics (ONS) is the executive office of the UK Statistics Authority, a non-ministerial department which reports directly to Parliament. ONS is the UK government's single largest statistical producer. It compiles information about the UK's society and economy, and provides the evidence-base for policy and decision-making, the allocation of resources, and public accountability. The DirectorGeneral of ONS reports directly to the National Statistician who is the Authority's Chief Executive and the Head of the Government Statistical Service.

\section{The Government Statistical Service}

The Government Statistical Service (GSS) is a network of professional statisticians and their staff operating both within the Office for National Statistics and across more than 30 other government departments and agencies.

\section{Contacts}

\section{This publication}

For information about the content of this publication, contact Andrew Barnard.

Telephone: 01633455951

Email: andrew.barnard@ons.gsi.gov.uk

\section{Other customer enquiries}

ONS Customer Contact Centre

Tel: 08456013034

International: +44(0)8456013034

Minicom: 01633815044

Email: info@statistics.gsi.gov.uk

Fax: 01633652747

Post: Room 1.101, Government Buildings, Cardiff Road, Newport, South Wales NP10 8XG

www.ons.gov.uk

\section{Media enquiries}

Tel: 08456041858

Email: media.relations@ons.gsi.gov.uk

\section{Copyright and reproduction}

(C) Crown copyright 2011

You may re-use this information (not including logos) free of charge in any format or medium, under the terms of the Open Government Licence.

To view this licence, go to: www.nationalarchives.gov.uk/doc/open-governmentlicence/

or write to the Information Policy Team, The National Archives, Kew, London TW9 4DU

email: psi@nationalarchives.gsi.gov.uk

Any enquiries regarding this publication should be sent to: info@statistics.gsi.gov.uk

This publication is available for download at: www.ons.gov.uk 


\section{Summary}

The ONS analysis of The effects of taxes and benefits on household income, most recently published in May 2011, examines how the Government's intervention, through taxes and cash benefits, redistributes income among households. The amount by which taxes and benefits redistribute income from richest to poorest, known as their redistributive effect (see text box, 'Measuring income inequality') is usually measured by comparing inequality before and after they are added. This periodic analysis updates 'The redistribution of household income 1977 to 2006/07 article' published by ONS in 2008. However, it goes further, by separating the redistributive effects over time into two parts, (i) the size of taxes and benefits, and (ii) the rate at which taxes and benefits redistribute income.

The analysis, which is for the period 1980 to 2009/10, shows that:

- Taxes made little difference to income inequality throughout the period. This was because direct taxes reduced inequality and indirect taxes increased inequality by roughly the same amounts and cancelled each other out. Cash benefits therefore played the largest part in reducing income inequality

- Cash benefits became increasingly targeted towards reducing income inequality, as measured by the benefit concentration coefficient. However, between 2004/05 and 2009/10, cash benefits became slightly less targeted towards reducing inequality

- Direct taxes also became increasingly targeted towards reducing income inequality, as measured by the tax concentration coefficient

- Indirect taxes in the UK have been regressive over the entire period

- On average, cash benefits reduced income inequality by 15 percentage points over the period, direct taxes reduced inequality by 3 percentage points, whereas indirect taxes increased inequality by 4 percentage points, as measured by the Gini coefficient

- Non-contributory benefits, such as income support, child benefit and housing benefits, were more targeted towards reducing inequality from 1984 onwards, compared with contributory benefits. Prior to 1984 , contributory benefits, such as the state retirement pension and incapacity benefits were more targeted towards reducing inequality

- Retired households received the majority of cash benefits. However, cash benefits were more targeted towards reducing inequality among non-retired households. The latter is still true after removing the state retirement pension from the analysis (the state retirement pension is defined here as a cash benefit). 


\section{Concepts and sources}

The analyses presented here are based on data from the Living Costs and Food survey (LCF) - formerly named the Expenditure and Food survey (EFS) and before that the Family Expenditure Survey ${ }^{1}$ (FES)). The survey sample size has varied from 6,900 households in 1980 to 5,700 households in 2008/09. The estimates presented are for calendar years up until 1992, and for financial years from 1993/94 onwards.

This analysis focuses on the income of households:

- Household members receive income from employment, private pensions and other non-governmental sources as original income.

- Cash benefits, such as the state retirement pension and income support, are added to original income to form gross income.

- Direct taxes like income tax are subtracted from gross income to give household disposable income.

- Indirect taxes, which are taxes on spending such as VAT, are subtracted from disposable income to give post-tax income.

The effects of taxes and benefits on household income analysis also includes estimates of benefits from services received from the Government either free or subsidised at the point of use - benefits in kind. These benefits, when added to posttax income form final income. However, because these figures are notional, they are not appropriate to equivalise, or to calculate inequality estimates for final income. Therefore, no analysis of final income is included in this analysis. Incomes are equivalised throughout using the McClements scale to adjust for differences in household composition.

\section{Results for all households}

\section{Trends in income inequality}

Figure 1 presents Gini coefficients (see the 'Measuring income inequality' textbox for an explanation of this term) for original income (income before taxes and benefits), gross income (after cash benefits are added), disposable income (after cash benefits are added and direct taxes subtracted) and post-tax income (after cash benefits are added and both direct and indirect taxes are subtracted) for all households. The figure shows that income inequality, as measured by the Gini coefficient, increased during the 1980 s and has remained around the same level since then.

The 1980s were characterised by a large increase in inequality, although the trend differed according to the measure of income. For original income, the Gini coefficient rose throughout this period. However, the pattern for the Gini coefficient for gross, disposable and post-tax incomes were slightly different: for the first half of the decade the inequality of these measures of income were stable; this was then followed by rises in the second half of the 1980s.

1. From 2001/02, the Expenditure and Food survey (EFS) began including households that contained a proxy interview. Analysis of the 2001-02 data has revealed that the inclusion of proxy interviews increased average gross weekly household income. There is therefore a small discontinuity in the series between 2000/01 and 2001/02. 
The figures for the 1990s show a different story. Inequality of original income was relatively stable for the first two years, and then showed a small rise up to 1993/94. For the rest of the decade, the Gini coefficient for original income remained fairly stable meaning that the level of inequality remained roughly unchanged. In contrast, inequality of disposable income reduced slowly from 1990 until the mid-1990s, although it did not fully reverse the rise seen in the previous decade. In the late 1990s, inequality of gross, disposable and post-tax income rose slightly once again but flattened off by the end of the period.

Figure 1 also shows that there was a fall in inequality of gross, disposable and posttax income between 2001/02 and 2004/05; possibly due to the introduction of tax credits. The Gini coefficients for all measures of income increased between 2004/05 and $2006 / 07$. There was also a decrease in inequality for gross income and disposable income between 2006/07 and 2007/08. Inequality then increased slightly for original, gross and disposable income between 2007/08 and 2008/09 and then decreased between 2008/09 and 2009/10.

Figure 1: Gini coefficients for ALL households, 1980-2009/10

Percentages

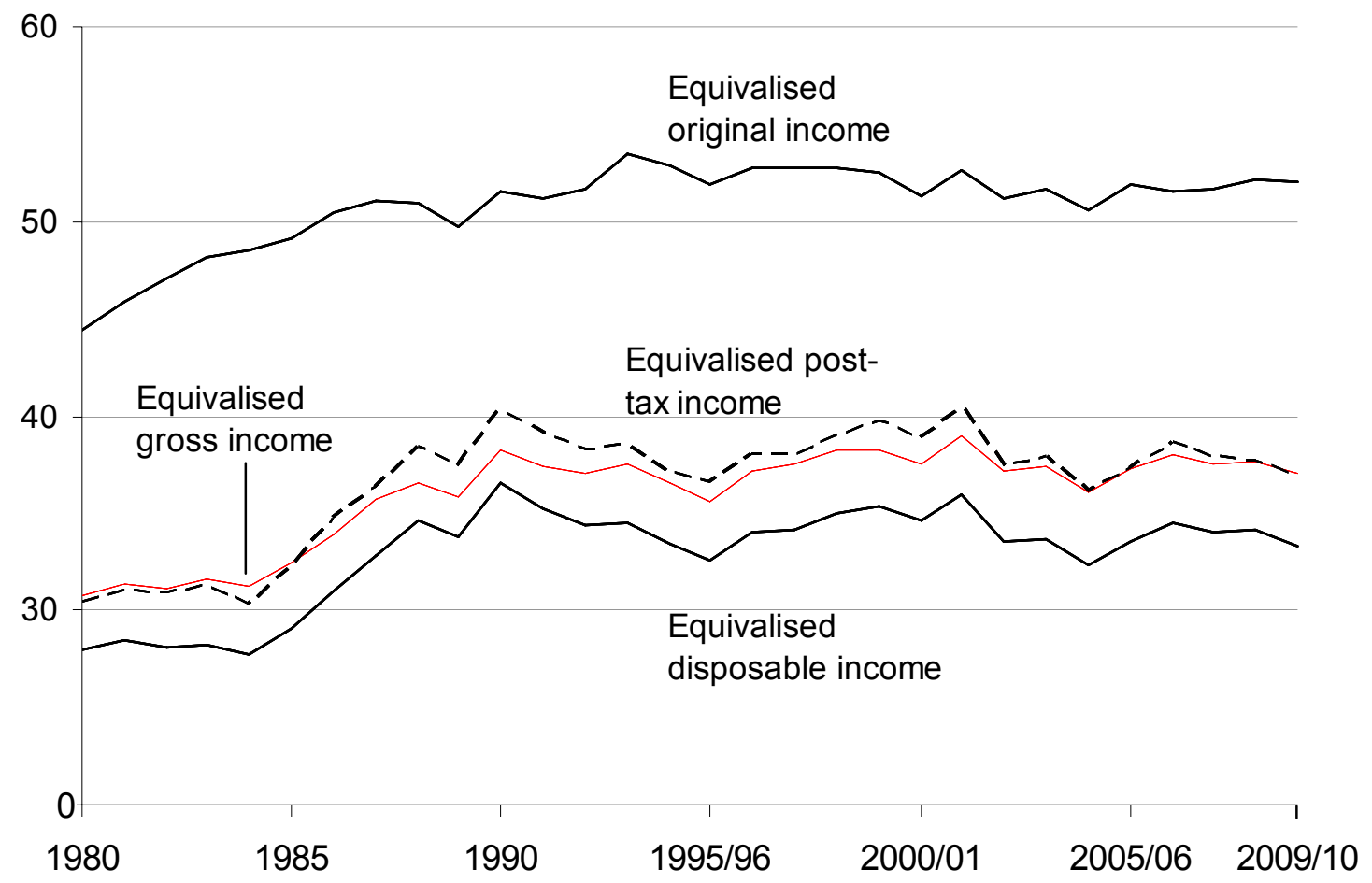

Source: Office for National Statistics

One way of measuring the redistributive effects of taxes and benefits is by comparing the respective Gini coefficients, before and after taxes and benefits are taken into account. Thus, comparing the Gini coefficients for original and gross incomes shows the change in inequality caused by cash benefits, comparing the Gini coefficients for gross and disposable income shows the change caused by direct taxes, so on. 
Figure 2 shows the change in inequality caused by taxes and benefits for all households between 1980 and 2009/10. The figure shows that reductions in inequality between 1980 and 2009/10 were largely caused by the effects of cash benefits. Cash benefits reduced inequality by an average of 15 percentage points over the period; direct taxes reduced inequality by an average of 3 percentage points; and indirect taxes increased inequality by an average of 4 percentage points.

Figure 2: Change in Gini coefficients because of cash benefits and taxes for ALL households, 1980-2009/10

Percentage points

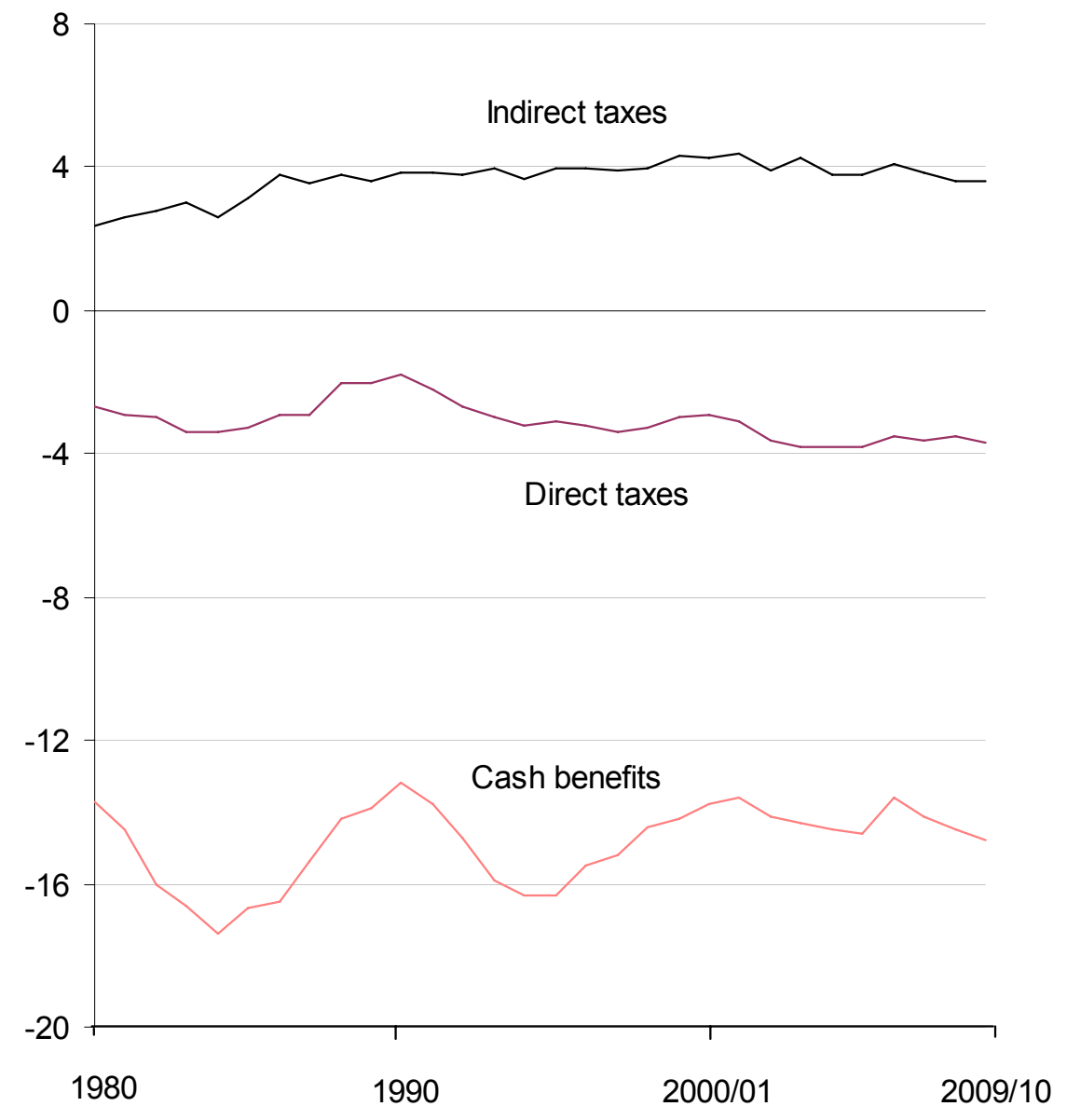

Source: Office for National Statistics

\section{Shares of cash benefits and direct taxes}

Redistribution from a tax or benefit perspective refers to both the size of the tax or the benefit, which can be measured by the average rate of the tax or benefit as a proportion of income ${ }^{2}$, and the progressivity of the tax or benefit. Figure 3 shows the size of cash benefits and direct and indirect taxes expressed as a percentage of household gross income. Cash benefits, as a proportion of gross income, were smallest in 1990 and represented 13 per cent of household gross income. Cash

\footnotetext{
${ }^{2}$ Households who receive no benefit or pay no direct taxes have been included in the calculation of the average benefit
} and average tax rates, respectively. 
benefits, as a proportion of income, were largest in 1984, representing 17 per cent of household gross income.

Figure 3: Cash benefits, direct tax and indirect tax as proportions of household gross income, 1980-2009/10

Percentages
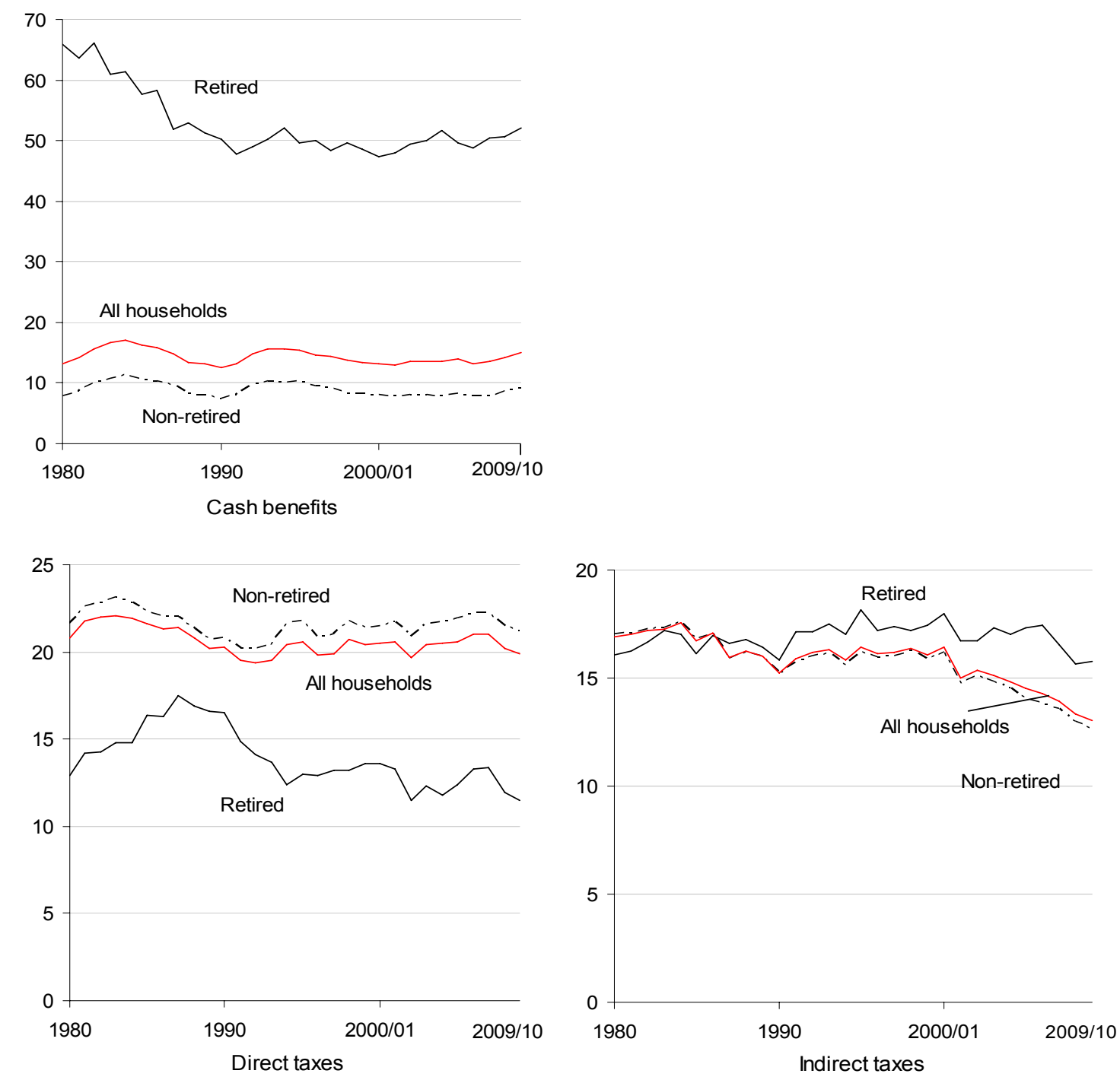

Source: Office for National Statistics

Cash benefits are proportionally larger for the incomes of retired households (defined as households where more than 50 per cent of the total gross household income is received by retired household members) compared to that for non-retired households. This is largely due to the state retirement pension. However, retired households saw their share of cash benefits decline from 66 per cent of gross income in 1980 to 52 per cent in 2009/10, because of increases in the prevalence and size of private pensions. Non-retired households, on the other hand, saw their share fluctuate during the same period. Cash benefits for non-retired households rose to 11 per cent of gross income in 1984 from 8 per cent in 1980. However cash benefits declined after 1984 to make up 7 per cent of gross income in 1990. Cash benefits fluctuated during most of 
the 1990s and remained between 8 per cent and 9 per cent of households' gross income between 2000/01 and 2008/09 and accounted for 9 per cent of household gross income in 2009/10.

The share of direct taxes as a proportion of gross income was highest in 1983 for all households, accounting for 22 per cent of gross income. They accounted for 15 per cent and 23 per cent of retired and non-retired households' gross income, respectively, in the same year. Direct taxes were lowest in 1992, representing 19 per cent of household gross income. The share of direct taxes was again smaller for retired households than for non-retired households. This analysis does not include a detailed investigation of the various policy changes and their effects on cash benefits and direct taxes that occurred over the period. These policy effects were covered in the previous ONS analysis, 'The redistribution of household income 1977 to 2006/07' (Jones et al, 2009).

The share of indirect taxes as a proportion of gross income was highest in 1984, when it made up 18 per cent of gross income. They made up similar proportions of retired and non-retired household's income, 17 and 18 per cent respectively, in the same year. The proportion decreased for non-retired households - in 2009/10 indirect taxes made up 13 per cent of gross income, a 5 percentage points fall from the value in 1984. However, the proportion for retired households remained more stable over the period, and in 2009/10 stood at 16 per cent of gross income.

\section{Measuring income inequality}

The effects of taxes and benefits on income inequality can be measured using the Gini coefficient. The Gini coefficient is one of the most widely used summary measures of the degree of inequality in an income distribution. Graphically, the Gini coefficient can be represented by the Lorenz curve. The Lorenz curve maps the cumulative income share against the cumulative share of the population. The Gini coefficient is calculated by taking the ratio of the area of the Lorenz curve for the income distribution of analysis and the area of Lorenz curve for perfect equality. The Gini coefficient takes values from 0 to 100 per cent, where a value of zero would indicate that each household had an equal share of income, while higher values indicate greater inequality.

A common way to measure the distributional impact of taxes and benefits is by examining how targeted the tax or benefit structure is when compared to a given income distribution. This has also been referred to as the progressivity of the tax or benefit. Kakwani (1977) defined progressivity as disproportionality in taxes, that is, their effect on the richest compared with the effect on the poorest.

The disproportionality of the tax or benefit is calculated using the concentration coefficient. The concentration coefficient is calculated in a similar way as the Gini coefficient, but is calculated using the concentration curve rather than the Lorenz curve. A concentration curve is generated by plotting the cumulative distribution of benefits or taxes on the $y$-axis against the cumulative distribution of population ranked by income on the x-axis. The concentration coefficient can take values between -100 and 100 ; a value of -100 means that the richest household received all the benefits (or the poorest household paid all the taxes), and a value of 100 means 
that the poorest household received all the benefits (or the richest household paid all the taxes).

If a tax concentration coefficient increases over time then taxes are becoming more progressive, while if a benefit concentration coefficient falls over time then benefits are becoming more progressive. Generally speaking, a negative benefit concentration coefficient or a positive tax coefficient means that they are progressive and act to reduce to the level of inequality. However, this will not always be the case. For benefits, as long as the benefit concentration coefficient is less than the respective Gini coefficient, they would act to reduce inequality. For taxes, a concentration coefficient that is larger than the respective Gini coefficient will act to reduce inequality.

The overall redistributive effect of taxes or benefits is then a result of two factors:

- The disproportionality of the tax or benefit. This measures the rate at which the tax or benefit reduces inequality.

- The relative size of the tax or benefit as a proportion of income. This can be referred to as the average tax or benefit rate.

\section{The effects of cash benefits for all households}

In addition to the relative size of taxes and benefits, the effectiveness of taxes or benefits in reducing income inequality is the other factor that determines the size of the redistribution of income. This is measured using the concentration coefficient for taxes or benefits (see the 'Measuring income inequality' textbox for an explanation of these terms) and is referred to as their 'disproportionality'. Figure 4 shows the disproportionality of benefits, measured by the benefit concentration coefficient, along with the average benefit rate for all households, with the shaded areas representing periods of economic recession. The figure also presents a three year moving average for the benefit concentration coefficient. Cash benefits have become more progressive since the early 1980 s as measured by the benefit concentration coefficient. However, there was a slight increase in the cash benefit concentration coefficient between 2004/05 and 2009/10. This means that cash benefits became less targeted towards reducing inequality during that period.

The figure shows that cash benefits, as measured by the average benefit rate, has fluctuated according to the general economic conditions - the rate rose during and immediately after the 1980 s and 1990s recessions and fell during the following boom years - with the exception of the late 2000s when cash benefits were rising before the recession had started. This to be expected, since for example, during and immediately after the recessions more people claimed unemployment related benefits. The figure also shows that the peak in the 1990s was smaller than the peak in the 1980s, while the troughs remained at roughly the same levels.

During the 1980 s recession, cash benefits became slightly less progressive and this was accompanied by an increase in their average size. This means that although cash benefits increased during the 1980 s recession, they were less targeted at reducing inequality. The mid and late 1980 s saw the decline in average cash benefits while at the same time cash benefits became more progressive. The decline in average cash 
benefits between 1987 and 1989 was largely driven by reductions in housing benefit, unemployment benefit and income support/ supplementary benefit over the period.

There was a rise in average cash benefits and levels of disproportionality at the start of the 1990 s recession, similar to the 1980 s recession. This means that the amount of cash benefits available to households increased and this was targeted towards reducing inequality. The period after the 1990 s recession - the mid-1990s - saw an increase in average cash benefits and levels of disproportionality also increased steadily. The late 1990 s to mid-2000s saw a decline in average cash benefits but a rise in the levels of disproportionality. Average cash benefits increased slightly at the start of the 2008/09 recession and became less progressive. The state retirement pension, incapacity benefit, tax credits and statutory maternity pay/allowance were the main drivers of the increase in average cash benefits between 2007/08 and 2008/09. Although average cash benefits increased between 2008/09 and 2009/10, the respective levels of progressivity declined.

\section{Figure 4: Disproportionality of cash benefits vs. their average rate ${ }^{1}$ for ALL households,} 1980-2009/10

Percentages

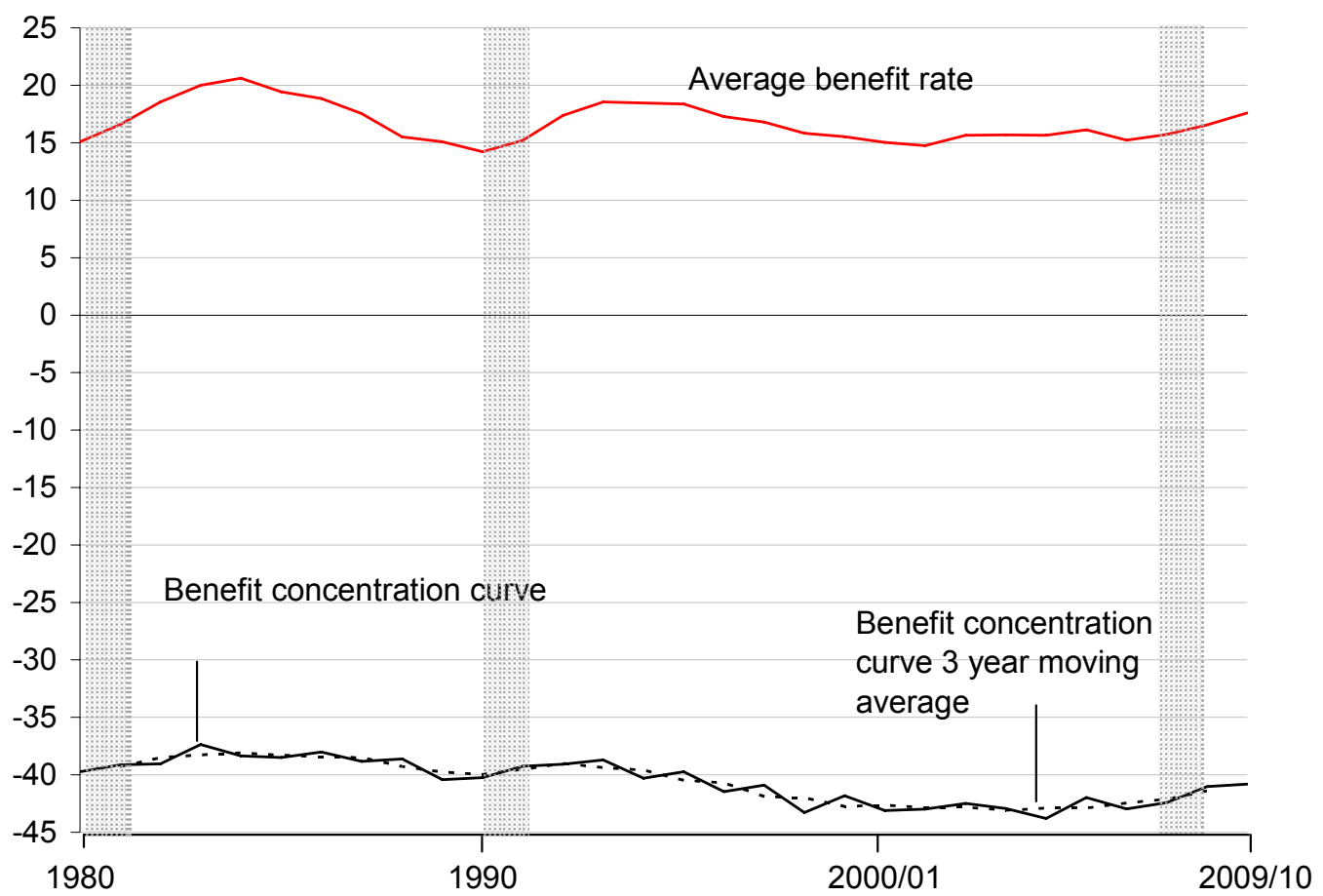

Notes:

1 Calculated as a proportion of original income to be consistent with the cash benefit concentration coefficient.

Reading note: A decreasing benefit concentration coefficient over time means that benefits are becoming more progressive, whereas an increasing benefit concentration coefficient means that benefits are becoming less progressive.

Source: Office for National Statistics

The disproportionality of cash benefits varies significantly across the different types of cash benefit. There are two broad types of cash benefit: contributory benefits, which are paid from the National Insurance Fund, to which individuals and their employers 
make contributions while working; and non-contributory benefits, many of which are means-tested. Contributory benefits include the state retirement pension, widow's benefits and statutory maternity allowance. Non-contributory benefits include income support and pension credit, attendance allowance, disability living allowance and housing benefit. Income from non-contributory benefits increased more rapidly than income from contributory benefits between 1980 and 2009/10.

Figure 5 shows that contributory benefits were more progressive than noncontributory benefits in the early 1980s. This means that contributory benefits acted more to reduce inequality than non-contributory benefits during that period.

Figure 5: Disproportionality of cash benefits by type, 1980-2009/10 Percentages

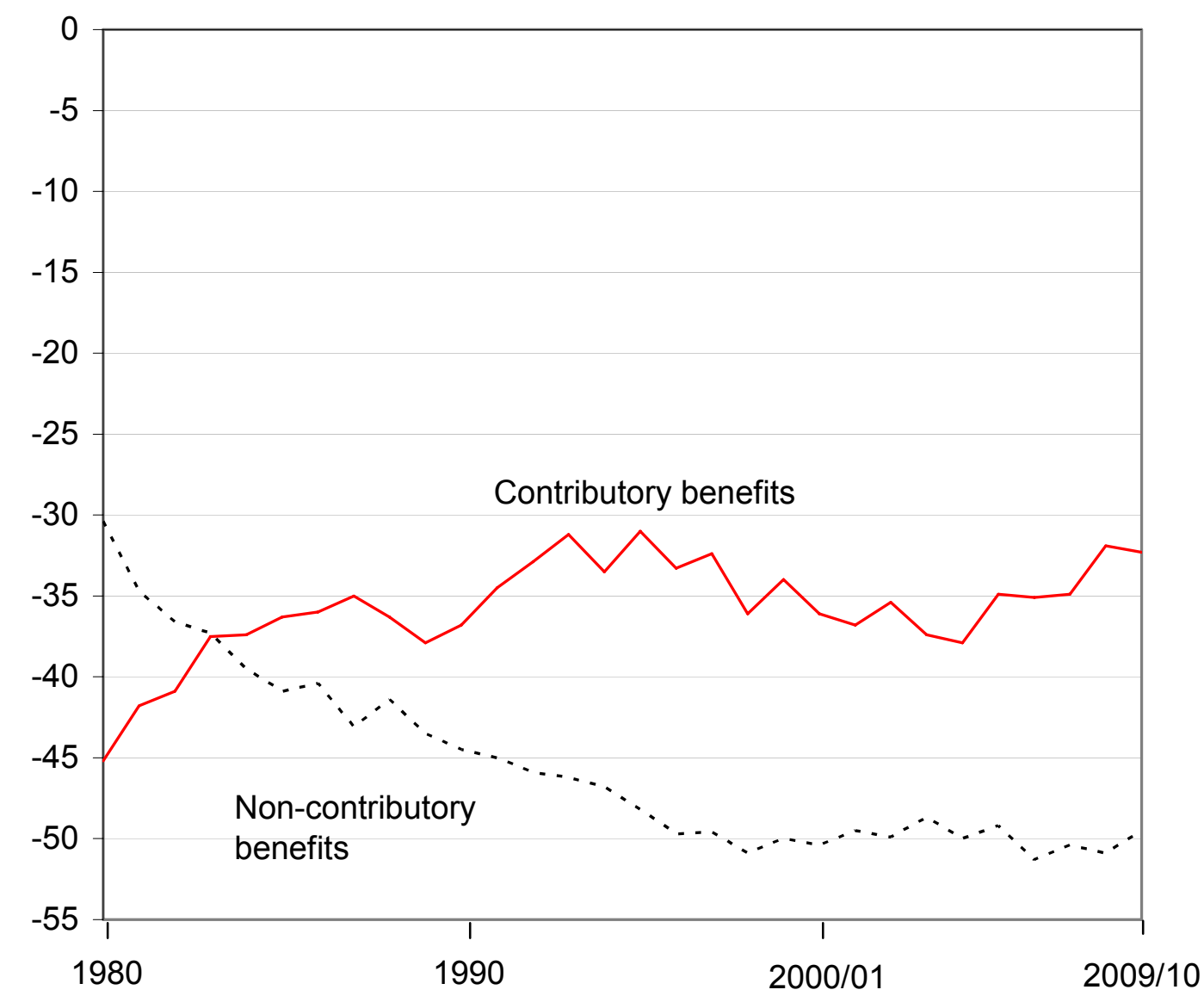

Reading note: A decreasing benefit concentration coefficient over time means that benefits are becoming more progressive, whereas an increasing benefit concentration coefficient means that benefits are becoming less progressive.

Source: Office for National Statistics

However, from 1984 to 2009/10, non-contributory benefits became more progressive than contributory benefits. Thus, from 1984, non-contributory benefits have been more targeted than contributory benefits in reducing inequality. The increase in the progressivity of non-contributory benefits between 1984 and the early 1990s was due to an increase in the number of non-retired households with no earner. In addition, 
there were also increases in the types of non-contributory benefits available to low income households from the early 1980s. For instance, housing benefits were introduced in 1982-1983 and there was increase in low income households claiming income support (known as supplementary benefit before 1988/89).

\section{The effects of direct taxes for all households}

Figure 6 shows the disproportionality of direct taxes with the average direct tax rate for all households from 1980 to 2009/10. Direct taxes consist of income taxes, employees' National Insurance contributions and local taxes. Higher values of the concentration coefficient imply that richer households pay a larger proportion of their income in direct tax - which means these taxes are more progressive. The figure shows that direct taxes in the UK have been progressive, as measured by the concentration coefficient. Direct taxes were less progressive in the late 1980 s and early 1990 s compared with the late 1990 s and early 21 st century. This means that direct taxes acted more to reduce inequality in the late 1990s and early 21st century compared with the late 1980 s and early 1990s. The decline in average direct tax rates between 1980 and 2009/10 were largely caused by changes in income taxes.

Figure 6: Disproportionality of direct taxes vs their average rate ${ }^{1}$ for ALL households, 1980 2009/10 2

Percentages

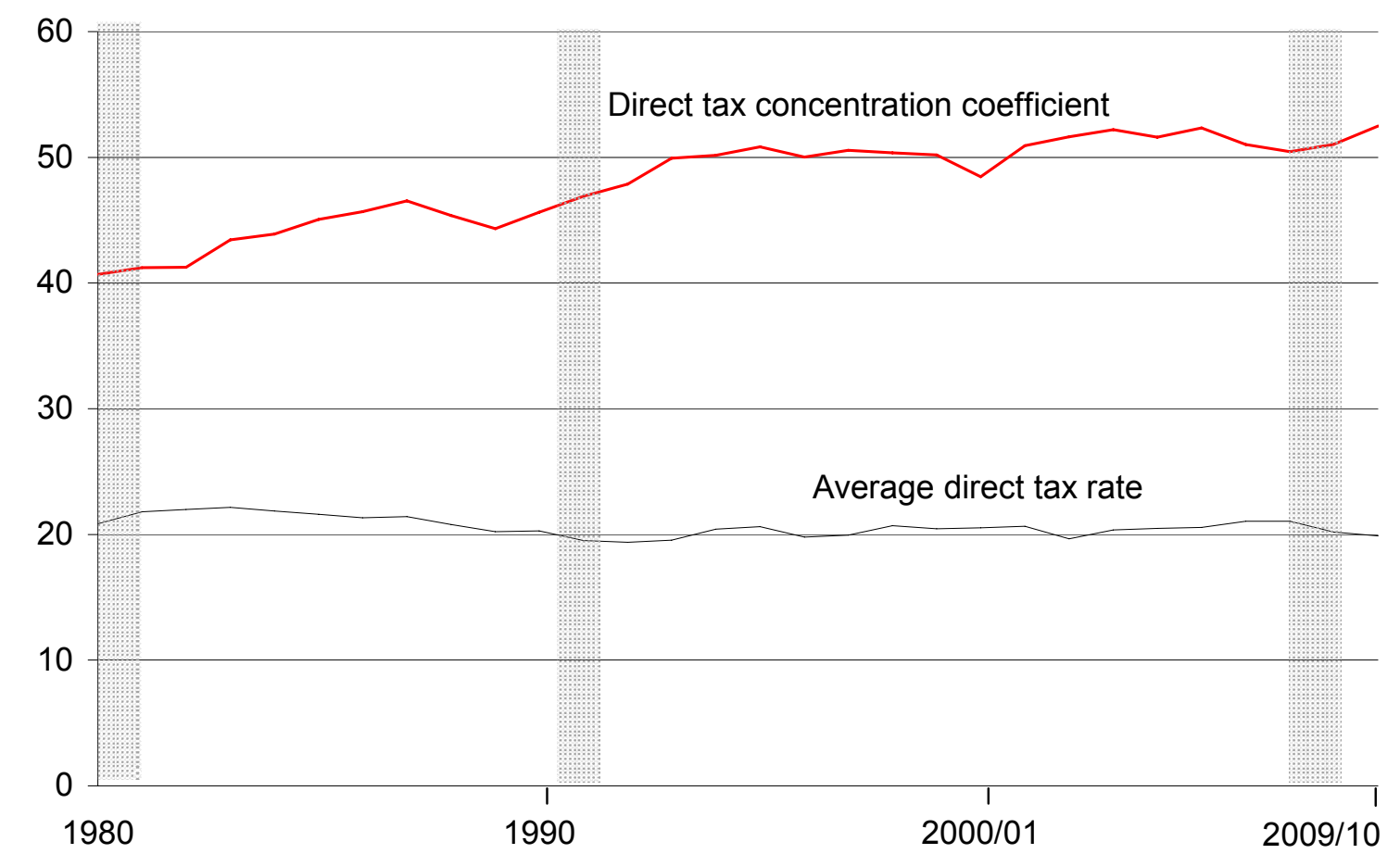

Notes:

1 Calculated as a proportion of gross income to be consistent with the direct tax concentration coefficient.

2 Shaded areas on the graph represent periods of recession.

Reading note: An increasing tax concentration coefficient over time means that taxes are becoming more progressive (or less regressive), whereas a decreasing tax concentration coefficient means that taxes are becoming less progressive (or more regressive).

Source: Office for National Statistics 
Average tax rates increased during the 1980s recession, due to rises in National Insurance contributions, while levels of disproportionality also increased. This implies that rising taxes during this recession could have served to reduce inequality, as households in higher income groups were taxed more than households in lower income groups.

The mid to late 1980 s were characterised by high disproportionality of taxes and declining average tax rates. This means that, on average, households during this period paid relatively smaller and more progressive taxes. The decline in direct taxes was due to cuts in both income taxes and the rate for National Insurance contributions. Average tax rates declined after the 1990s recession, whilst levels of disproportionality continued to increase during the first two years of the 1990s recession. Between 1992 and 1998/99, levels of disproportionality and average tax rates stayed quite stable; declining slightly in 1996/97.

Average tax rates fluctuated between $1999 / 00$ and $2007 / 08$. Levels of disproportionality also fluctuated during this period, but were higher than levels experienced during the 1980 s and the 1990 s recessions. The $2008 / 09$ recession was characterised by a decline in average tax rates, while disproportionality increased slightly between 2007/08 and 2009/10. There was a further decline in average tax rates between 2008/09 and 2009/10, whilst levels of disproportionality increased during this period.

The impact of the different direct taxes and the Gini coefficient for gross income is shown in Figure 7. Figure 7 shows levels of disproportionality of income tax, employees' National Insurance contributions and local taxes as well as the Gini coefficient for gross income. The figure shows that income tax has been more targeted towards reducing inequality than employees' National Insurance contributions from 1980 to 2008/09; although they have both been targeted towards reducing inequality during this period. The figure also shows that local taxes have been regressive, and as such, not targeted at reducing inequality, as the concentration coefficient for local taxes was less than the Gini coefficient for gross income.

The 1980s recession was characterised by an increase in the disproportionality of both employees' National Insurance contributions and income tax. This implies that they both acted to reduce inequality. Employees' National Insurance contributions and income tax became increasingly progressive between 1985 and 1987 . The 1990s recession followed a similar pattern to the 1980s recession as there was an increase in levels of disproportionality for income tax and employees' National Insurance contributions. However, levels of disproportionality were higher than the $1980 \mathrm{~s}$ recession. This means that income tax and employees' National Insurance contributions were more targeted at reducing income inequality in the 1990s recession than in the 1980 s recession. Levels of disproportionality for income tax and employees' National Insurance contributions fluctuated between the mid-1990s and $2007 / 08$. Levels of disproportionality for income tax and employees' National Insurance contributions also increased during the 2008/09 recession. 
Figure 7: Disproportionality of direct taxes by type and Gini coefficient for gross income, 1980-2009/10

Percentages

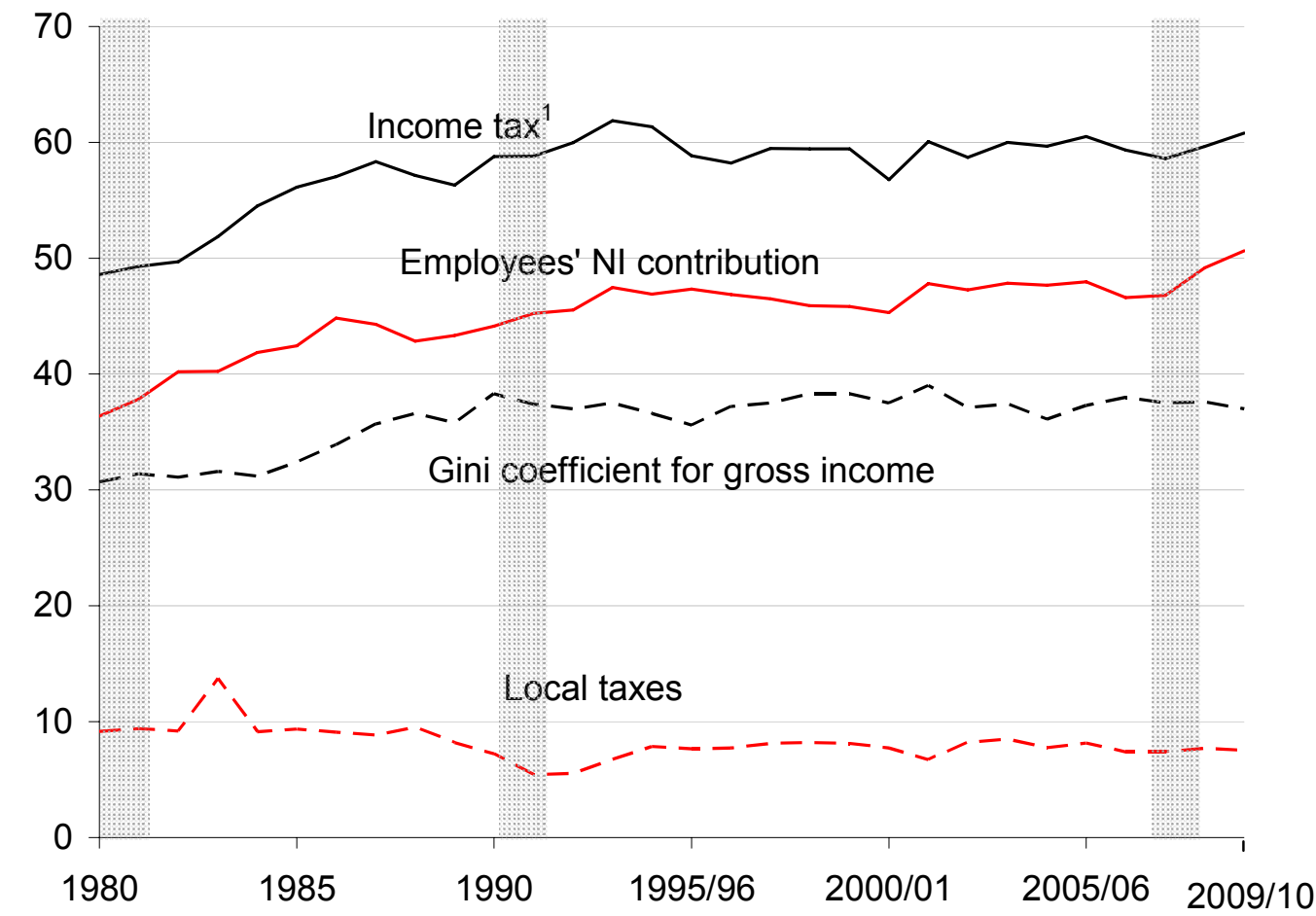

Notes:

1 Income tax is income tax less tax relief.

Reading note: An increasing tax concentration coefficient over time means that taxes are becoming more progressive (or less regressive), whereas a decreasing tax concentration coefficient means that taxes are becoming less progressive (or more regressive).

Source: Office for National Statistics

\section{The effects of indirect taxes for all households}

Figure 8 shows the disproportionality of indirect taxes with the average tax rate for all households from 1980 to 2009/10. Indirect taxes consist of taxes paid on spending, such as VAT, duties on alcohol, tobacco and fuel, and taxes incurred by businesses which are passed onto customers through the prices of goods and services.

As with the results for direct taxes, higher values of the concentration coefficient for indirect taxes mean that richer households pay a larger proportion of their income in these taxes. Indirect taxes in the UK have been regressive, as measured by the concentration coefficient, throughout the period, and therefore increase income inequality. Between 1980 and 2004/05 the concentration coefficient followed a relatively flat trend, indicating that indirect became neither more nor less regressive over this period. The concentration coefficient rose slightly between 2004/05 and 2009/10, meaning that indirect taxes became slightly less regressive. 
Figure 8: Disproportionality of indirect taxes vs their average rate ${ }^{1}$ for ALL households, 1980-2009/10

Percentages

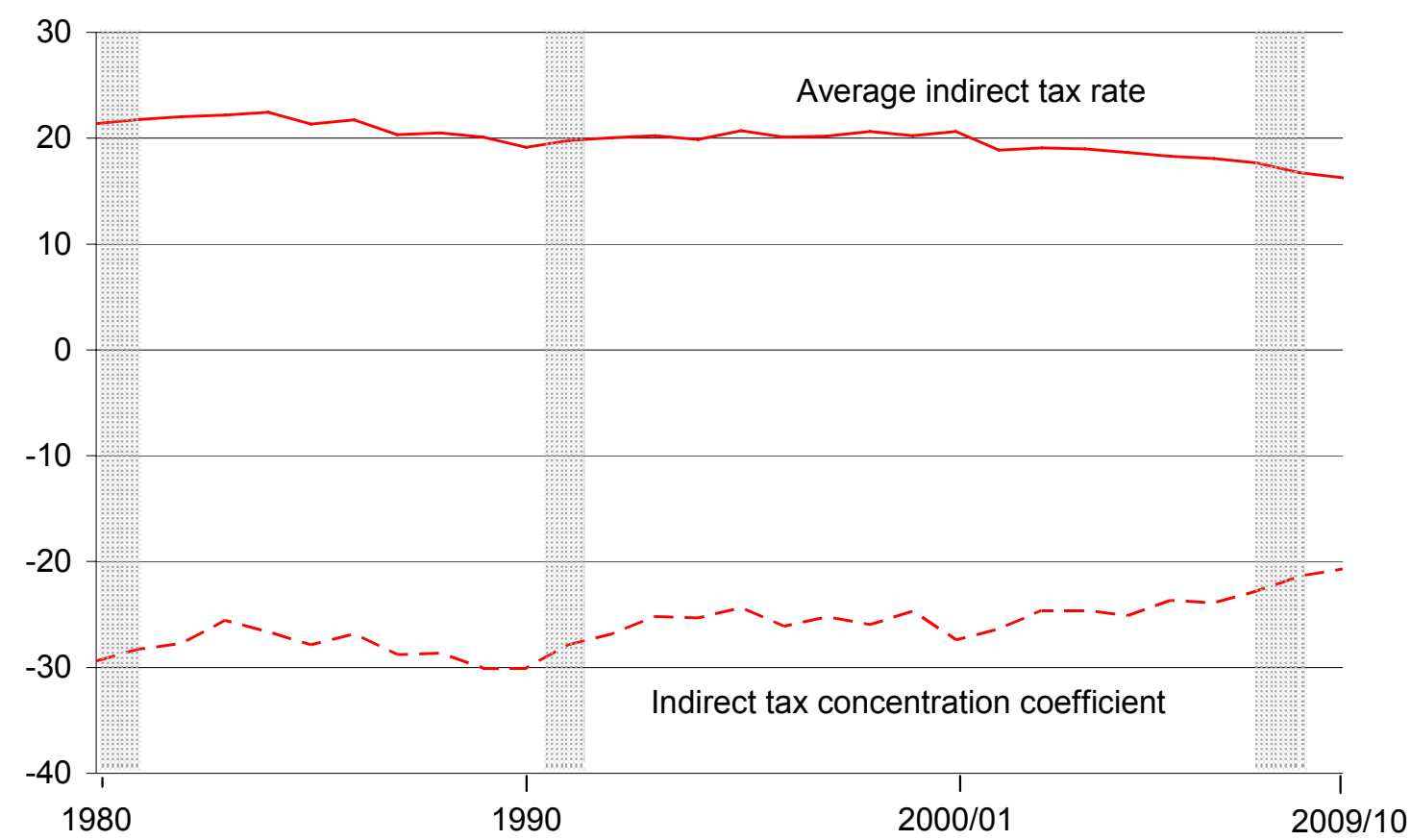

Notes:

1 Calculated as a proportion of disposable income to be consistent with the indirect tax concentration coefficient

2 Shaded areas on the graph represent periods of recession.

Reading note: An increasing tax concentration coefficient over time means that taxes are becoming more progressive (or less regressive), whereas a decreasing tax concentration coefficient means that taxes are becoming less progressive (or more regressive).

Source: Office for National Statistics

\section{Results for retired households}

In The effects of taxes and benefits on household income analysis, a household is defined as retired when more than 50 per cent of the total gross household income is received by retired members of the household.

Retired households have distinct income patterns compared to the non-retired households. In order to maintain a stable level of consumption during their lifetime, households tend to save during their working years and then draw on these savings during retirement through, for example, pensions. Due to the small sample sizes involved, only limited analysis is provided for the effects of direct and indirect taxes.

Figure 9 presents the Gini coefficients for retired households in the UK from 1980 to $2009 / 10$. The figure shows that before taxes and benefits, there is a higher degree of inequality among retired households, as measured by original income than for all households. However, the figure also shows that inequality as measured by original income declined by 13 percentage points during the period. 
After the intervention of taxes and benefits there is a large reduction in inequality, because the state retirement pension is included as a cash benefit. Thus, inequality for retired households as measured by disposable income becomes smaller than inequality for all households. Between 1980 and 1990, the Gini coefficient for retired households, measured using disposable income, increased by 10 percentage points. This increase was due to the absence of real growth in income from the state retirement pension as well as the strong growth in income from private pensions and investments (Jones et al, 2008). Despite periods of both rising and falling inequality since 1990, inequality of disposable income for retired households remained higher in the late 1990 s and 2000 s than it was in the early 1980 s.

Figure 9: Gini coefficients for RETIRED households, 1980-2009/10 Percentages

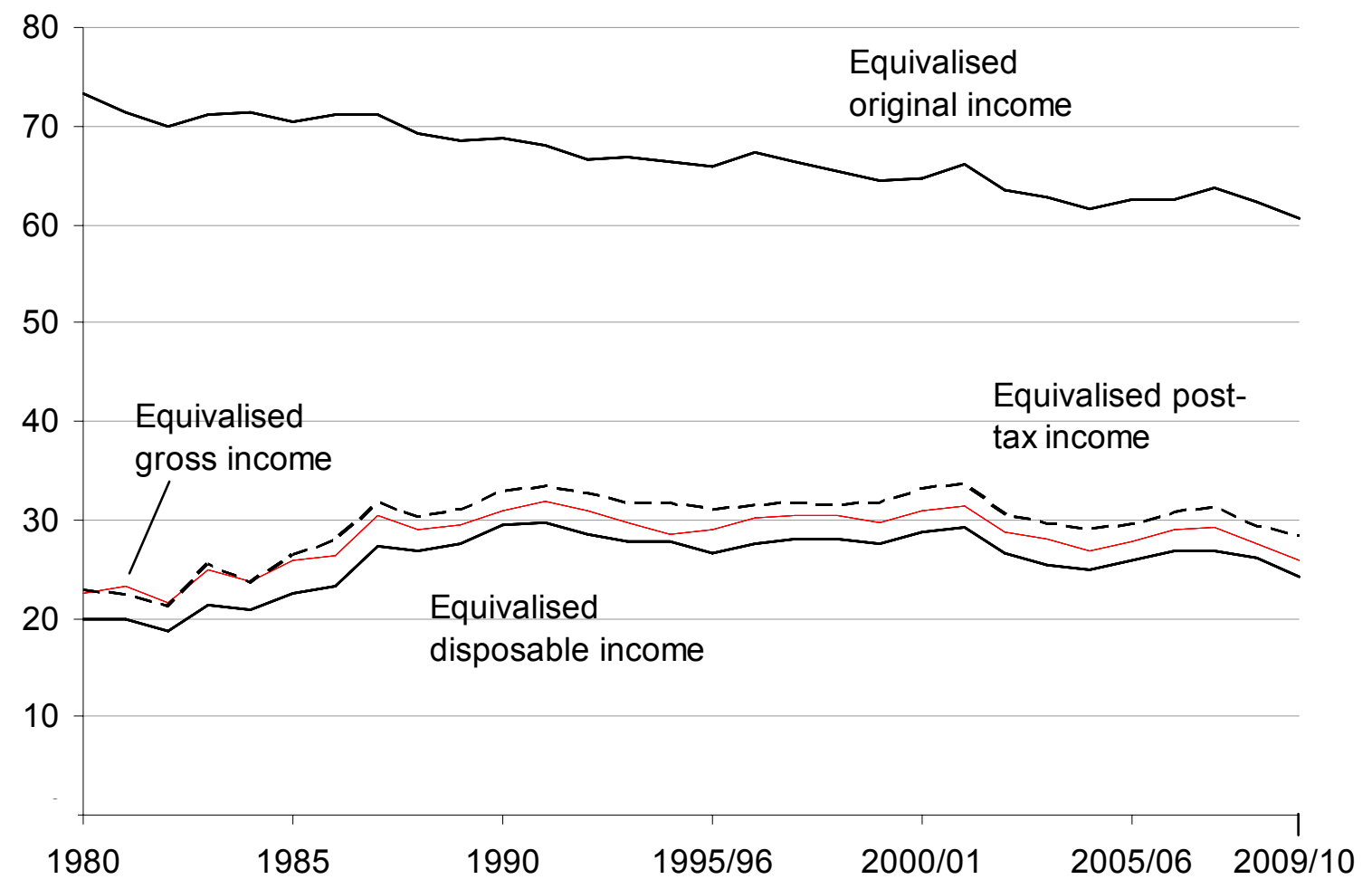

Source: Office for National Statistics

The reduction in inequality caused by taxes and benefits for retired households is shown in Figure 10. Reductions in inequality between 1980 and 2009/10 were largely driven by cash benefits and the largest overall reductions were observed in 1980 and 1982. Smaller overall reductions in inequality were observed in 2000/01 and 2006/07.

On average, cash benefits reduced inequality among retired households by 39 percentage points between 1980 and 2009/10 whilst, direct taxes reduced inequality by 2 percentage points and indirect taxes increased inequality by 4 percentage points. The smaller reduction by direct taxes is because retired households pay a lower proportion of their income as tax than non-retired households (see Figure 3 ). 
Figure 10: Change in Gini coefficients because of cash benefits and taxes for RETIRED households, 1980-2009/10

Percentage points

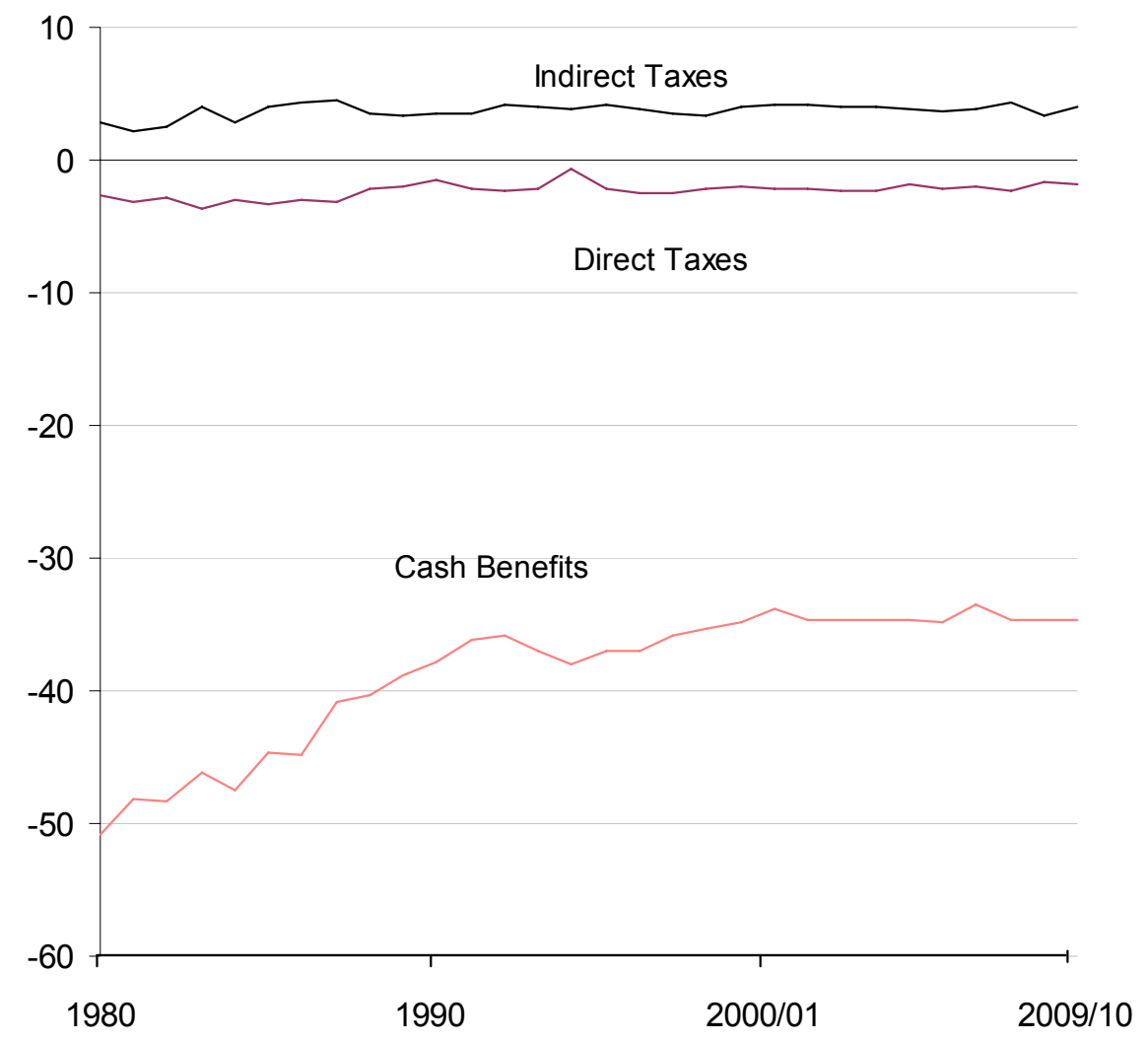

Source: Office for National Statistics

\section{The effects of cash benefits for retired households}

Figure 11 shows the interaction of the disproportionality of benefits with the average benefit rate for retired households. The concentration coefficient for benefits shows that benefits for retired households in the UK were progressive since 1980. However, cash benefits are more progressively distributed among non-retired households than among retired households.

In addition, average benefit rates for retired households were much higher and more stable over time compared to average benefit rates for all households. Also, levels of disproportionality among retired households were much lower than levels of disproportionality among all households. This means that the larger cash benefits received by retired households were not as targeted towards reducing inequality among retired households compared with all households on average. This is because, as previously mentioned, in this analysis the state retirement pension is included as a benefit. The amount of state retirement pension each household receives is based on their National Insurance contributions throughout their working lives; which is, in turn, dependent in part on their income. Analysis done after removing the state retirement pension from cash benefits increased the levels of progressivity among retired households. The average benefit concentration coefficient for 1980 to 2009/10 including state retirement pension was -7 per cent. However, when state retirement 
pension was excluded from cash benefits, the equivalent figure was -32 per cent. Therefore, the inclusion of the state retirement pension as a cash benefit reduces the progressivity of cash benefits among retired households.

Figure 11: Disproportionality of benefits vs their average rate ${ }^{1}$ for RETIRED households, 1980-2009/10 2

Percentages

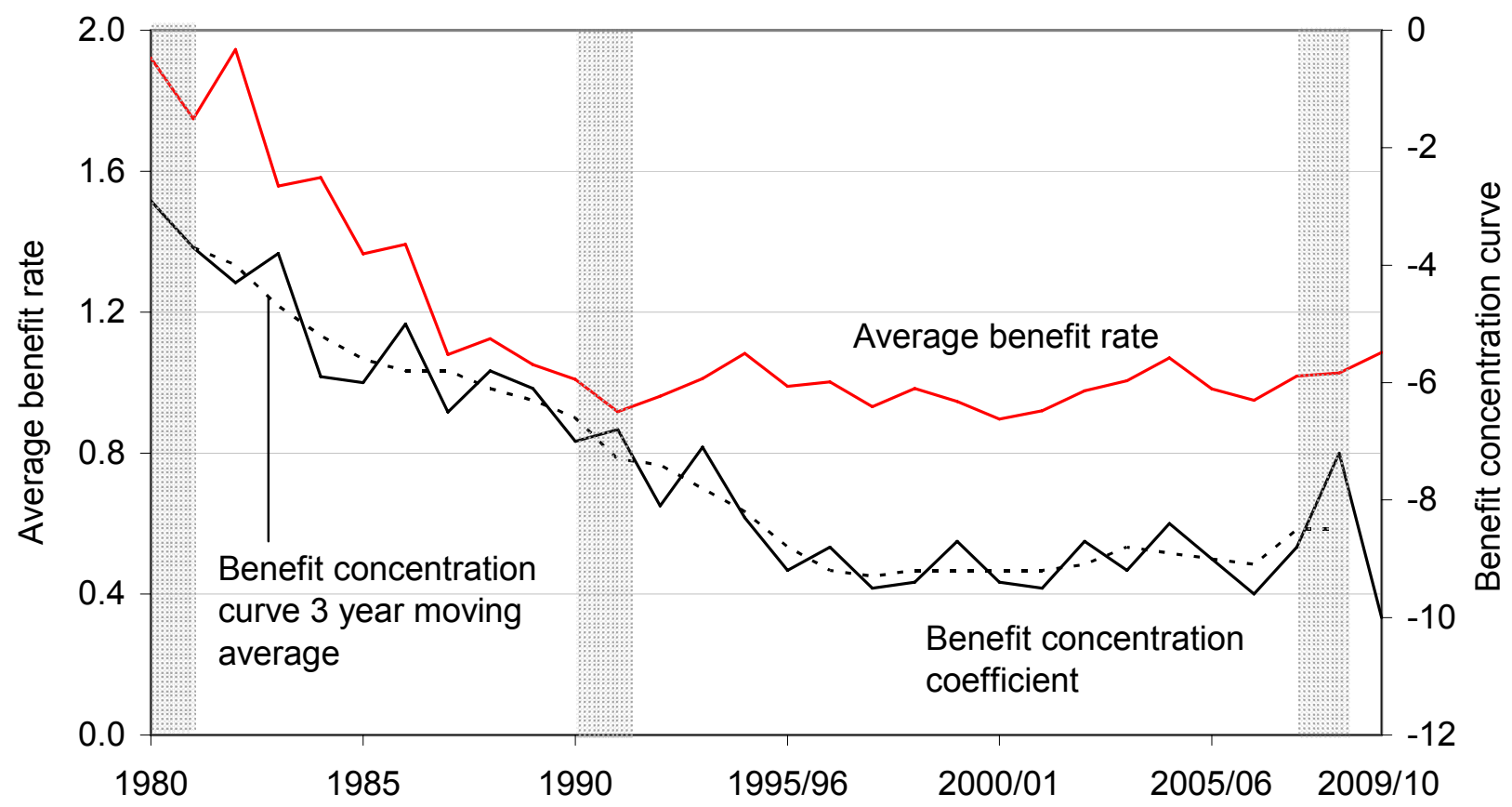

Notes:

1 Calculated as a proportion of original income to be consistent with the cash benefit concentration coefficient.

2 Shaded areas on the graph represent periods of recession.

Reading note: A decreasing benefit concentration coefficient over time means that benefits are becoming more progressive, whereas an increasing benefit concentration coefficient means that benefits are becoming less progressive.

Source: Office for National Statistics

The 1980 s recession was characterised by a decline in average benefit rates for retired households - between 1980 and 1981 - and an increase in average benefit rates at the end of the economic downturn - between 1981 and 1982. Levels of disproportionality of benefits however, increased steadily during the recession. This implies that although cash benefits declined during the recession, low income retired households still received a greater share of the cash benefits available to retired households. Average benefit rates decreased steadily during much of the mid-1980s and the early 1990s. However, levels of disproportionality of cash benefits increased during this same period.

Regarding average benefit rates, the 1990 s recession was similar to the 1980 s recession - characterised by a decline in the rate at the start of the recession and an increase at the end of the recession. Levels of disproportionality increased at the start of the recession (between 1989 and 1990) but declined at the end of the recession 
(between 1990 and 1991). This means that declining cash benefits reduced the share of cash benefits for low income retired households. Average benefit rates and the level of disproportionality fluctuated between 1995/96 and 2006/07. Between 2006/07 and $2007 / 08$, cash benefits increased but levels of disproportionality declined and as such inequality of gross income increased by 0.3 percentage points. The 2008/09 recession was characterised by an increase in average benefits while levels of disproportionality of cash benefits declined slightly. Average benefits rates increased between 2008/09 and $2009 / 10$, caused by an increase in non-contributory benefits, whilst levels of disproportionality also increased sharply during this period.

\section{Conclusion}

Over the period 1980 to 2009/10, taxes overall made little difference to income inequality. This was because although direct taxes reduced inequality, indirect taxes increased inequality, and by roughly the same amounts. Cash benefits therefore played the largest part in reducing income inequality.

Direct taxes and cash benefits became increasingly targeted towards reducing income inequality as measured by the tax and benefit concentration coefficients, respectively. The combined effect of the trends in both the size of cash benefits and the benefit concentration coefficient was that the effect of cash benefits on inequality was largely unchanged between 1980 and 2009/10.

The combined effect of the size of direct taxes and the tax concentration coefficient was that there was an increase in the redistributive effect of direct taxes between 1980 and 2009/10 (see Figure 2). This effect, which was largely driven by the tax concentration coefficient, led to a small increase in the effect of direct taxes on inequality from the early 1990 s onwards.

Finally, between 1980 and 2004/05 indirect taxes became neither more, nor less regressive, although between 2004/05 and 2009/10 they became slightly less regressive. 


\section{REFERENCES}

Barnard A, Howell S, Smith R (2011) 'The effects of taxes and benefits on household income, 2009/10. Further analysis and methodology', Non-journal articles, pp 1-90. Available at:

http://www.statistics.gov.uk/articles/nojournal/Taxes Benefits 0910 Methodology.pd $\underline{f}$

Carerra S (2010) 'An expenditure-based analysis of the redistribution of household income', Economic \& labour Market Review, Volume 4, No 3, pp 31-43. Available at: http://www.statistics.gov.uk/cci/article.asp?id=2373.

Creedy J (2003) 'Non-uniform consumption taxes: A 'blunt redistributive instrument'? Fiscal Policy, Inequality and Welfare, Research on economic inequality, Volume 10, pp1-19.

Howell, S (2011) 'How indirect taxes can be regressive and progressive', Non-journal articles, pp 1-10. Available at:

http://www.statistics.gov.uk/articles/nojournal/indirect-taxes-1404.pdf.

Jones F, Annan D and Shah S (2008) 'The redistribution of household income 1977 to 2006/07', Economic \& labour Market Review, Volume 3, No 1, pp 31-43. Available at: http://www.statistics.gov.uk/cci/article.asp?ID =2083.

Jones F, Annan D and Shah S (2008) 'The distribution of household income 1977 to 2006/07', Economic \& labour Market Review, Volume 2, No 12, pp 18-31. Available at: http://www.statistics.gov.uk/cci/article.asp?ID $=2082$.

Kakwani N (1977) 'Measurement of Tax Progressivity: An International Comparison', Economic Journal, Volume 87, pp 71-80.

Stern N (1990) 'Uniformity versus selectivity in indirect taxation', Economics and Politics, Volume 2, pp 83-108. 